\title{
Multiple sclerosis with pseudotumoral demyelinating lesions in a female adolescent presenting with an optic neuritis
}

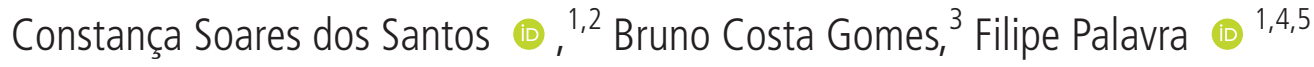

\section{${ }^{1}$ Center for Child}

Development-Neuropediatrics Unit, Hospital Pediátrico, Centro Hospitalar e Universitário de Coimbra, Coimbra, Portugal ${ }^{2}$ Pediatrics Department, Centro Hospitalar Cova da Beira, Covilha, Portugal

${ }^{3}$ Medical Image DepartmentNeuroradiology Unit, Centro Hospitalar e Universitário de Coimbra, Coimbra, Portugal ${ }^{4}$ Coimbra Institute for Clinical and Biomedical Research (iCBR), Faculdade de Medicina, Universidade de Coimbra,

Coimbra, Portugal

${ }^{5}$ Clinical Academic Center of Coimbra, Coimbra, Portugal

\section{Correspondence to} Dr Constança Soares dos Santos;

constanca.s.santos@gmail.com

Accepted 8 June 2021
(D) Check for updates

(C) BMJ Publishing Group Limited 2021. No commercial re-use. See rights and permissions. Published by BMJ.

\begin{tabular}{l}
\hline To cite: dos Santos CS, \\
Costa Gomes B, \\
Palavra F. BMJ Case \\
Rep 2021:14:e244837. \\
doi:10.1136/bcr-2021- \\
244837 \\
\hline
\end{tabular}

\section{DESCRIPTION}

A previously healthy 13-year-old female adolescent presented with right retrobulbar eye pain, worse with vertical eye movements, followed by decreased visual acuity, evolving for 4 days. She complained of fatigue in the previous month and she reported no similar previous episodes. On admission, she had mild visual loss $(0.8)$ in the right eye with a relative afferent pupillary defect, blurring of optic margins of the right papilla and a right central scotoma. She showed no dyschromatopsia and no other changes in the neurological examination. The brain MRI showed two tumefactive demyelinating lesions with an open-ring enhancement after gadolinium administration (figure 1) and additional typical demyelinating lesions (disseminated in space) without enhancement. Cerebrospinal fluid analysis showed no changes, oligoclonal banding was negative and anti-AQP4 and anti-MOG antibodies were negative. These findings were consistent with multiple sclerosis (MS) with pseudotumoral demyelinating lesions (MS-PL) and she completed 5 days of intravenous methylprednisolone, with full visual recovery. At the follow-up consultation, she started

\section{Learning points}

- Multiple sclerosis with pseudotumoral demyelinating lesions (MS-PL) is a rare variant of the disease and it can represent a diagnostic problem.

- MS-PL may present with clinical features disproportionate to the lesion dimensions and may show a good prognosis despite the great size of lesions.

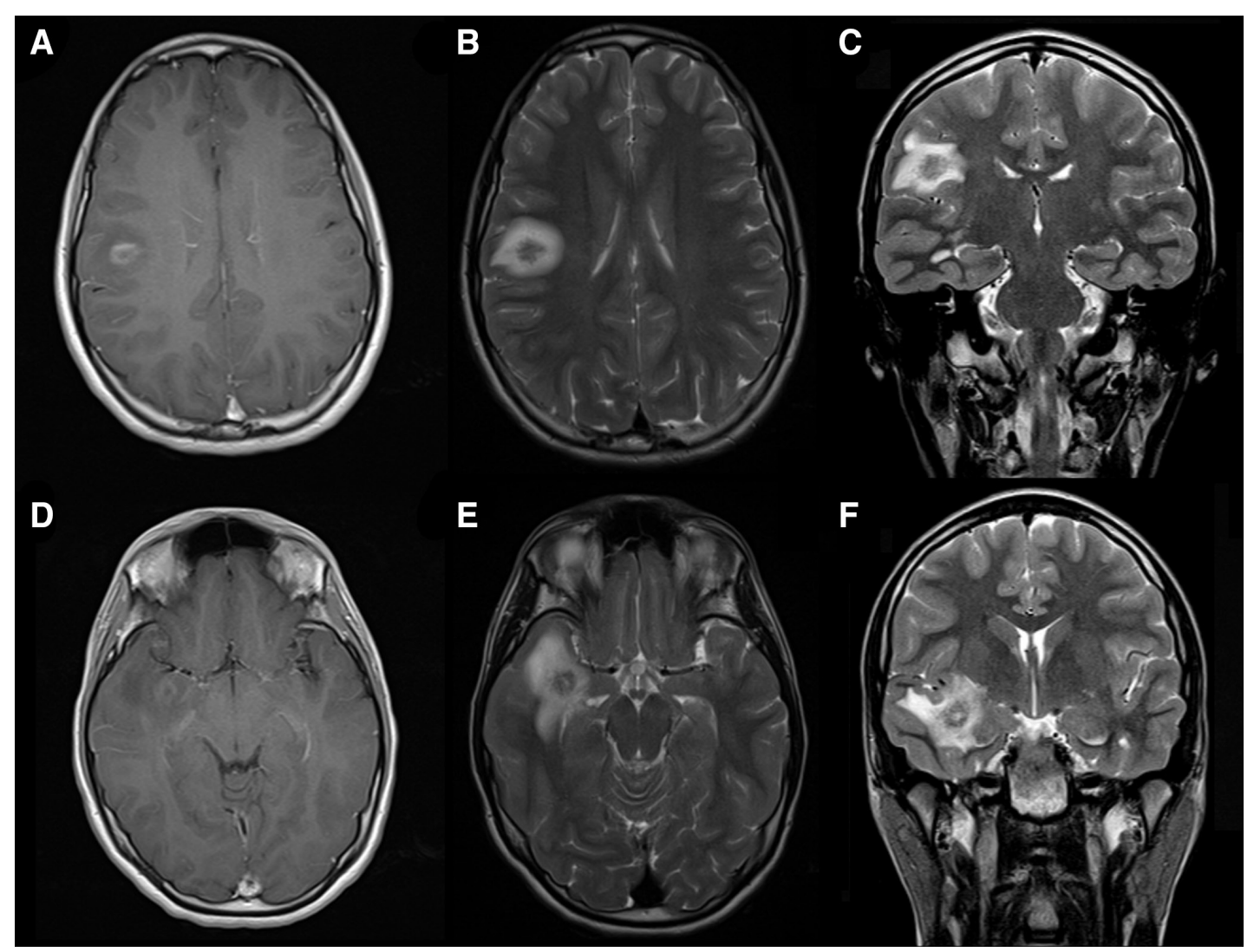

Figure 1 Tumefactive demyelinating lesions: A-C A large subcortical lesion in the posterior-inferior area of the right frontal lobe and D-F A large lesion in the anterior and medial area of the right temporal lobe, with extension to the insular and opercular regions. A,D Axial T1-weighted images after gadolinium injection, with the typical incomplete ring enhancement pattern. B,E Axial T2-weighted images. C,F Coronal T2-weighted images. 
intravenous natalizumab. She showed regression of previous lesions and no new injuries in subsequent MRI at 6, 12, 18 and 36 months. Three years after diagnosis, she is clinically stable (Expanded Disability Status Scale: 1.5), with no new relapses or complaints related to treatment.

MS, defined by recurrent episodes of demyelination in the central nervous system (CNS), disseminated in space and time, is the most prevalent chronic inflammatory disease of the CNS. In children, it has a wide range of clinical manifestations, including optic neuritis, or a range of focal or multifocal neurological symptoms. In this case, although the clinical presentation was limited to ocular symptoms, brain MRI showed large demyelinating lesions. Typical MS lesions identified in MRI are usually smaller than $0.6 \mathrm{~cm} .{ }^{1}$ Rarely, some patients present with larger demyelinating lesions at their first event. When larger than $2 \mathrm{~cm}$, these lesions are considered tumefactive or pseudotumoral. ${ }^{2-4}$ Although rare (incidence of 3:1 000 000/year), MS-PL is more common in women in their second and third decades of life and is usually manifested by multifocal symptoms such as persistent headache, impaired consciousness, focal signs or cognitive deficits. $^{25}$ Surprisingly, in our case, it occurred with few neurological deficits disproportionate to the lesion dimensions. MS-PL may pose diagnostic challenges: solitary lesions may be mistaken for primary tumours, abscess, metastasis or infarction, while multiple pseudotumoral lesions may suggest acute disseminated encephalomyelitis. $^{2-9}$ In our case, the presence of additional typical demyelinating lesions fulfilling McDonald's criteria for dissemination in time and space assisted in diagnosing MS.

MS-PL is associated with higher hospitalisation rates and morbidity than conventional MS. ${ }^{10}$ Due to its significant inflammatory component, it may respond to corticosteroids, as shown in our case, with a reduction of the size of the lesions. ${ }^{9}$ Although its long-term evolution is still unclear, the complete disappearance of the lesions is unusual and residual deficits are frequent. ${ }^{10}$ Recurrence of pseudotumoral lesions, although uncommon, may occur. $^{6}$ The present case adds up to the few cases that have been described in the literature and may contribute to further understand the clinical picture of MS-PL in children and adolescents.
Contributors CSdS and FP contributed to the study conception and design. BCG and FP contributed to acquisition and interpretation of the images and data. The first draft of the manuscript was written by CSdS and all authors commented on previous versions of the manuscript and revised it critically for important intellectual content. All authors read and approved the final manuscript and agree to be accountable for all aspects of the work in ensuring that questions related to the accuracy or integrity of any part of the work are appropriately investigated and resolved.

Funding The authors have not declared a specific grant for this research from any funding agency in the public, commercial or not-for-profit sectors.

Competing interests None declared.

Patient consent for publication Parental/guardian consent obtained.

Provenance and peer review Not commissioned; externally peer reviewed.

\section{ORCID iDs}

Constança Soares dos Santos http://orcid.org/0000-0002-3423-2462

Filipe Palavra http://orcid.org/0000-0002-2165-130X

\section{REFERENCES}

1 Filippi M, Rocca MA, Ciccarelli O, et al. MRI criteria for the diagnosis of multiple sclerosis: MAGNIMS consensus guidelines. Lancet Neurol 2016;15:292-303.

2 Hardy TA. Pseudotumoral demyelinating lesions: diagnostic approach and long-term outcome. Curr Opin Neurol 2019;32:467-74.

3 de Medeiros FC, de Albuquerque LAF, Pittella JEH, et al. Open-ring enhancement in pseudotumoral multiple sclerosis: important radiological aspect. Case Rep Neurol Med 2014:2014:951690.

4 Seewann A, Enzinger C, Filippi M, et al. MRI characteristics of atypical idiopathic inflammatory demyelinating lesions of the brain : A review of reported findings. $J$ Neurol 2008:255:1-10.

5 Mauri-Fábrega L, Díaz-Sánchez M, Casado-Chocán JL, et al. Pseudotumoral forms of multiple sclerosis: report of 14 cases and review of the literature. Eur Neurol $2014 ; 72: 72-8$

6 Lebrato Hernández L, Díaz Sánchez M, Prieto León M, et al. Recurrent pseudotumoral relapses in multiple sclerosis: a case report. Mult Scler Relat Disord 2018;22:49-51.

7 Comi G. Multiple sclerosis: pseudotumoral forms. Neuro/ Sci 2004;25(Suppl 4):\$374-9.

8 Lin M, Reid P, Bakhsheshian J. Tumefactive multiple sclerosis masquerading as high grade glioma. World Neurosurg 2018;112:37-8.

9 Rissardo JP, Caprara ALF. Management of recurrent tumefactive multiple sclerosis: case report and literature review. Asian J Neurosurg 2018;13:893-6.

10 Silsby M, Sánchez P, Spies JM, et al. Investigation of tumefactive demyelination is associated with higher economic burden and more adverse events compared with conventional multiple sclerosis. Mult Scler Relat Disord 2019;35:104-7.

Copyright 2021 BMJ Publishing Group. All rights reserved. For permission to reuse any of this content visit

https://www.bmj.com/company/products-services/rights-and-licensing/permissions/

BMJ Case Report Fellows may re-use this article for personal use and teaching without any further permission.

Become a Fellow of BMJ Case Reports today and you can:

- Submit as many cases as you like

- Enjoy fast sympathetic peer review and rapid publication of accepted articles

- Access all the published articles

Re-use any of the published material for personal use and teaching without further permission

Customer Service

If you have any further queries about your subscription, please contact our customer services team on +44 (0) 2071111105 or via email at support@bmj.com.

Visit casereports.bmj.com for more articles like this and to become a Fellow 